\title{
OCHRONOSIS AS DIFFERENCIAL DIAGNOSIS OF SPONDYLOARTHRITIS: CASE REPORT
}

Betânia Longo (Hospital Universitário Evangélico Mackenzie, Curitiba, PR, Brasil), Leticia Cezar Araujo (Hospital Universitário Evangélico Mackenzie, Curitiba, PR, Brasil), Deborah Crystine Colombo (Hospital Universitário Evangélico Mackenzie , Curitiba, PR, Brasil), Juliana Delfino (Hospital Universitário Evangélico Mackenzie, Curitib, PR, Brasil), Carla Luchese Almeida (Hospital Universitário Evangélico Mackenzie, Curitiba, PR, Brasil), Anauá Fernanda Santos Cavalcante (Hospital Universitário Evangélico Mackenzie, Curitiba, PR, Brasil), Jady Elen Pontes (Hospital Universitário Evangélico Mackenzie , Curitiba, PR, Brasil), André Petry (Hospital Universitário Evangélico Mackenzie, Curitiba, PR, Brasil), Juliana Simioni (Hospital Universitário Evangélico Mackenzie, Curitiba, PR, Brasil), Thelma Larocca Skare (Hospital Universitário Evangélico Mackenzie, Curitiba, PR, Brasil), Ana Paula Beckhauser Campos (Hospital Universitário Evangélico Mackenzie, Curitiba , PR, Brasil)

\section{BACKGROUND}

Alkaptonuria (ACU) or endogenous ochronosis is an innate error in the metabolism of phenylalanine and tyrosine, with an autosomal recessive inheritance. It results from the complete deficiency of the enzyme homogentisic acid oxidase ( $\mathrm{HGO}$ ), leading to acid accumulation in various organs and tissues, with increased urinary excretion. Clinical manifestations include ochronous arthropathy, darkened pigmentation of cartilage and other conjunctival tissues, and blackened urine. Ocronotic arthropathy is the most disabling manifestation of the disease and affects primarily large joints and spine.

\section{CASE REPORT}

LCP, male, 56 years old. Referred by the orthopedist to investigate possible spondylarthritis due to changes in spinal image exams. He complained of pain in the lumbar / thoracic spine beginning at age 52 , as well as pain in the shoulders and knees. He denied any previous complaints. In the past the patient had undergone arthroscopy on the shoulders, being evidenced by orthopedic blackened cartilage during the procedure. Anamnesis directed to spondyloarthritis was negative, as well as HLA B27 screening. Imaging tests showed advanced synovitis on the shoulders. Magnetic Resonance of the thoracic spine showed erosions on vertebral plateaus, fatty metaplasia, and sacroiliac resonance showed subchondral bone edema and bone ankylosis. Both reports point to hypotheses of spondyloarthritis or depositional disease. Due to the fact that the patient was previously asymptomatic, in addition to the report of pigmented cartilage in shoulder arthroscopies, the diagnosis of ocrontic arthropathy was considered, and the diagnosis of the disease was confirmed by the homogentisic acid test in the urine, which was positive.

\section{CONCLUSION}

Ochronotic arthropathy typically arises between the third and fifth decades of life and progresses with advancing age, initially manifesting with pain in the lumbar spine and arthralgia of large joints, especially knees, shoulders and hips. Tendons and intervertebral discs may also be affected. There is no specific treatment for ACU. The initial approach is based on symptomatic measures, with analgesics, nonhormonal anti-inflammatory drugs (NSAIDs), physiotherapy, intra-articular infiltration with corticosteroids. A diet with tyrosine and phenylalanine restriction is targeted, which can prevent the progression of the disease. For advanced cases, total arthroplasty of shoulders, hips and knees is the treatment of choice. ACU is often confused with osteoarthritis or ankylosing spondylitis, being an important differential diagnosis. Although it is a rare disease, it is necessary to remember alcaptonuria as a cause of low back pain, especially in patients between the third and fifth decades of life. 